\title{
Effects of Capsiate Supplementation on Body Weight and Bone Mineral Density in Slightly Overweight Women: A Randomized, Doble-Blind, Placebo-Controlled Study
}

Gianmaria Salvio ( $\square$ gimmy133@hotmail.com )

AOU Ospedali Riuniti di Ancona: Azienda Ospedaliero Universitaria Ospedali Riuniti di Ancona Umberto I G M Lancisi G Salesi https://orcid.org/0000-0001-9290-5699

Massimiliano Petrelli

AOU Ospedali Riuniti di Ancona: Azienda Ospedaliero Universitaria Ospedali Riuniti di Ancona Umberto I G M Lancisi G Salesi

\section{Silvia Paolini}

AOU Ospedali Riuniti di Ancona: Azienda Ospedaliero Universitaria Ospedali Riuniti di Ancona Umberto I G M Lancisi G Salesi

\section{Veronica Baldini}

AOU Ospedali Riuniti di Ancona: Azienda Ospedaliero Universitaria Ospedali Riuniti di Ancona Umberto I G M Lancisi G Salesi

\section{Claudia Sbaffi}

AOU Ospedali Riuniti di Ancona: Azienda Ospedaliero Universitaria Ospedali Riuniti di Ancona Umberto I G M Lancisi G Salesi

\section{Stefania Basili}

AOU Ospedali Riuniti di Ancona: Azienda Ospedaliero Universitaria Ospedali Riuniti di Ancona Umberto I G M Lancisi G Salesi

\section{Antonio Giordano}

Polytechnic University of Marche: Universita Politecnica delle Marche

\section{Giancarlo Balercia}

AOU Ospedali Riuniti di Ancona: Azienda Ospedaliero Universitaria Ospedali Riuniti di Ancona Umberto I G M Lancisi G Salesi

\section{Saverio Cinti}

Polytechnic University of Marche: Universita Politecnica delle Marche https://orcid.org/0000-00030362-5017

\section{Research Article}

Keywords: brown adipose tissue, capsaicin, capsinoids, spices, osteoporosis 
Posted Date: February 9th, 2022

DOI: https://doi.org/10.21203/rs.3.rs-1335950/v1

License: (9) This work is licensed under a Creative Commons Attribution 4.0 International License. Read Full License 


\section{Abstract}

BACKGROUND: Overweight and obesity are highly prevalent conditions associated with premature morbidity and mortality worldwide. Capsiate, a nonpungent analogue of capsaicin, binds to capsaicin binds to TRP vanilloid 1 (TRPV1) receptor, which is involved in adipogenesis, and could be effective as a weight-lowering agent.

METHODS AND RESULTS: Eighteen slightly overweight women were enrolled in this randomized, dobleblind, placebo-controlled study. Nine patients were included in the capsiate intervention group and received $9 \mathrm{mg} /$ day of capsinoids whereas other 9 patients received placebo for 8 weeks. All patients underwent weight and waist circumference assessment before and after treatment. Body composition and bone mineral density were also detected by Dual-energy X-ray absorptiometry (DXA). Fourteen patients completed the study. The treatment with capsiate or placebo for 8 weeks was not associated to significant changes in weight or waist circumference. After treatment, there was a significant improvement of Bone Mineral density (BMD values measured at the spine in the capsiate group (1.158 vs $\left.1.106 \mathrm{~g} / \mathrm{cm}^{2},+4.7 \% ; p=0.04\right)$, but not in the group treated with placebo. Similarly, the capsiate group showed a $9.1 \%$ increase $(p=0.05)$ in the adipose tissue and an $8.5 \%$ decrease in lean mass measured at the supraclavicular level, whereas these changes were not statistically significant in the placebo group.

CONCLUSION: Treatment with capsiate for 8 weeks led to negligible changes in body weight in a small sample of slightly overweight women, but our findings suggest a potential effect of capsaicin on bone metabolism in humans.

\section{Introduction}

Overweight and obesity are pathological conditions determined by excess adipose tissue that are highly prevalent in the general population and represent a major public health problem worldwide. According to the World Health Organization (WHO) definitions, different degrees of overweight are categorized by the amount of excessive adipose tissue established using the body mass index (BMI), which is calculated by dividing the body weight (in kilograms) by the square of the height (in meters) [1]. Normal BMI range is therefore defined by a BMI $18.5-24.9 \mathrm{~kg} / \mathrm{m}^{2}$, whereas $\mathrm{BMI} \geq 25 \mathrm{~kg} / \mathrm{m}^{2}$ and $\mathrm{BMI} \geq 30 \mathrm{~kg} / \mathrm{m}^{2}$ identify overweight and obese subjects, respectively. In addition, subjects with $\mathrm{BMI} \geq 40 \mathrm{~kg} / \mathrm{m}^{2}$ are considered severely obese [2]. In the world, obesity affects $15 \%$ of women and about $10 \%$ of men [1]. America and Europe are the regions with the highest prevalence of overweight and obesity worldwide, and the prevalence of both these conditions doubled since 1980 [1, 2]. To date, overweight affects $64.2 \%$ and 49.6\% of American and European population, respectively, whereas obesity is present in $28.3 \%$ and $19.6 \%$ of Americans and Europeans [2]. In Italy, the prevalence of overweight and obesity is slightly lower than other European countries (31.8\% and $8.9 \%$ ) and the trends over time are not so unfavorable, partly due to the "Mediterranean diet" and to better dietary habits [3]. By the way, obesity is a chronic progressive disease associated to premature mortality and disability [4], and every effort should be made to counteract it. Currently approved anti-obesity drugs include orlistat, liraglutide, and the combination 
naltrexone-bupropion, but they are associated to significant gastrointestinal adverse events and their efficacy remains modest [5].

Capsiate, together with dihydrocapsiate and nordihydrocapsiate, belongs to capsinoids, a group of substances with a molecular structure analogue to capsaicin found in "CH-19 Sweet" (Capsicum annuum L.), a nonpungent cultivar of red pepper [6]. According to recent findings, common dietary spice can bind to different transient receptor potential (TRP) channels [7]. In particular, capsaicin binds to TRP vanilloid 1 (TRPV1) receptor, which is also activated by thermal stimuli and which function in vivo is to detect noxious heat eliciting a sensation of burning pain [8]. Capsiate, due to its lipophilicity and aqueous stability, can activate TRPV1 receptor in the gut, but not in the oral cavity, and can induce its biological effects without producing nociceptive response [6, 9]. Since TRPV1 receptor plays a key role in biological functions implicated in adipogenesis, including modulation of energy metabolism, pre-adipocytes differentiation and cytokine signaling [7], capsiate could be a promising agent for treatment of obesity. According to the findings of a recent meta-analysis, capsaicin or capsinoids ingestion leads to increased energy expenditure in subjects with $\mathrm{BMI}>25 \mathrm{~kg} / \mathrm{m}^{2}$ (but not in those with $\mathrm{BMl}<25 \mathrm{~kg} / \mathrm{m}^{2}$ ) confirming the potential role for capsaicin-like substances as appropriate agents for treatment of obesity [9].

The aim of the present study is therefore to investigate whether the administration of capsiate is able to induce significant weight loss and change body composition in a population of overweight subjects.

\section{Material And Methods}

\section{PATIENTS}

Slightly overweight (BMI $26-29 \mathrm{~kg} / \mathrm{m}^{2}$ ) female subjects aged 20-40 years old were recruited among the patients of the clinic of endocrinology and metabolic diseases of the university hospital "Ospedali Riuniti" of Ancona from April 2017 to December 2018. Inclusion criteria were the following: ability to understand and provide informed consent, no cigarette smoking, and sedentary lifestyle (less than 3 days/week of physical activity during the 6 months before the study. Conversely, patients were excluded on the basis of the following criteria: any specific dietary regime other than a normocaloric diet; allergy to chili pepper; daily intake of more than 2 cups of tea or coffee, 4 cans of caffeine-containing soft drinks or 3 glasses of alcoholic beverages; daily assumption of chili pepper; regular assumption of antidepressants or weightreducing drugs; drug abuse; contraindications to Dual-energy X-ray absorptiometry (DXA) examination; pregnancy and breastfeeding. The study protocol was approved by the local ethics committee (number of protocol 2015-0222 OR).

\section{STUDY DESIGN}

Eligible subjects were randomly allocated in a 1:1 ratio to the Capsiate or placebo group using a random numbers generator. Capsiate capsules contain capsinoids (capsiate, dihydrocapsiate, and nordihydrocapsiate in a 7:2:1 ratio) extracted from $\mathrm{CH}-19$ Sweet (Capsicum annuum) and were provided by Ajinomoto Co., Inc. (Tokyo, Japan). Each capsule contained $1.5 \mathrm{mg}$ of capsinoids and $199 \mathrm{mg}$ of a 
mixture of rapeseed oil and medium- chain triglycerides. Participants were instructed to take three capsules of Capsiate or placebo in each morning and evening of each day ( $9 \mathrm{mg} / \mathrm{day})$ for 8 weeks. The appearance, color, smell and taste of the Capsiate and placebo capsules were identical to maintain treatment blinding.

DXA examination: DXA was used to measure body composition and bone mineral density (BMD) with a Lunar Prodigy ${ }^{\circledR}$ densitometer (GE Healthcare, Madison, WI). The body composition and the BMD were assessed using whole body scans. In addition, the composition of two specific regions of interest (ROIs), at the mediastinal level (mROI) and at the supraclavicular level (sROI), corresponding to the point of highest accumulation of brown fat, was evaluated. The software used was Lunar Prodigy ${ }^{\circledR}$ enCore 2007 version 11.4. Z-score and T-score values were expressed as SD values and calculated according to the manufacturer's normative data.

\section{OUTCOMES}

Primary endpoint: mean difference between the two treatment groups in body weight reduction, defined as the absolute change in weight ( $\mathrm{kg}$ ) measured at baseline (W0) and after treatment (W8).

Secondary endpoints: Mean difference between the two treatment groups in waist circumference reduction, defined as the absolute change in waist circumference $(\mathrm{cm})$ measured at baseline and after treatment. Mean difference between the two treatment groups in modification of body composition (lean mass and fat mass, BMD, mediastinal and supraclavicular adipose tissue) using DXA. Modification is defined as the absolute change in in the various parameters of body composition measured at baseline and after treatment.

\section{STATISTICAL ANALYSIS}

Statistical analyses were performed using the Statistical Package for Social Sciences (SPSS) version 23.0 (SPSS Inc., Chicago, IL) for Microsoft Windows. Normal distribution for continuous variables was assessed using the Shapiro-Wilk test for normality if not evident from the histogram and/or normality graph. Data are shown respectively as mean \pm standard deviation (SD) or median and interquantile range (IQR) in case of normality or not. Comparison between groups was performed by T-test for independent samples in case of normality, and by Mann-Whitney U-test in case of non-normal distributions. Similarly, the T-test for dependent samples or the Wilcoxon signed-rank test were used to compare data before and after treatment. The required sample for the primary outcome was 15 , which was calculated to detect a significant change in body weight of $1.85 \mathrm{~kg}(\mathrm{SD}=2 \mathrm{~kg})$ after 8 weeks of treatment, with a statistical power of $80 \%$. Values of $p<0.05$ were considered statistically significant.

\section{Results}

Twenty-two slightly overweight female subjects were assessed for eligibility. After exclusion of 4 patients, 18 were recruited and randomized to Capsiate $(\mathrm{N}=9)$ or placebo $(\mathrm{N}=9)$. After treatment initiation, 3 
subjects ( 1 subjects from the Capsiate group and 2 subjects from the placebo group) were excluded for not taking the medication continuously, and one subject from the placebo group withdrew the consent. Fourteen subjects, 8 subjects in the Capsiate group and 6 subjects in the placebo group, completed the study (Figure 1). According to the study protocol, all the patients maintained a normocaloric diet. No harmful effects were observed in any group.

As shown in Table 1, the anthropometric characteristics at the baseline did not differ between the two groups. Similarly, baseline DXA parameters did not differ between the two groups (data not shown). After randomization, the two groups underwent 8 weeks of continuous treatment with capsiate or placebo. As shown in Table 2, absolute change in weight, $\mathrm{BMI}$ and waist circumference after treatment was negligible both for the CAPSIATE and the placebo group. Tables 3 and 4 report separately values of BMD evaluated on all bone segments in the two different groups. After treatment, there was a statistically significant improvement of BMD values of the vertebral column in the CAPSIATE group $\left(1.158 \mathrm{vs} 1.106 \mathrm{~g} / \mathrm{cm}^{2}\right.$, equal to an increase of $4.7 \% ; p=0.04$ ), whereas no significant changes were observed at any site in the placebo group.

Table 1

baseline characteristics of the population

\begin{tabular}{|llll|}
\hline & $\begin{array}{l}\text { Capsiate group } \\
(\mathbf{n = 8})\end{array}$ & $\begin{array}{l}\text { Placebo group } \\
(\mathbf{n = 6})\end{array}$ & \\
\hline Age (years) & $31.75 \pm 12.2$ & $30.3 \pm 13.7$ & $\mathrm{p}=0.84$ \\
\hline Height $(\mathrm{cm})$ & $162.6 \pm 4.9$ & $162.5 \pm 4.5$ & $\mathrm{p}=0.96$ \\
\hline Weight $(\mathrm{kg})$ & $70.4 \pm 10.7$ & $71.8 \pm 6.1$ & $\mathrm{p}=0.76$ \\
\hline BMI $(\mathrm{kg} / \mathrm{m} 2)$ & $26.9 \pm 5.7$ & $27.2 \pm 2.1$ & $\mathrm{p}=0.90$ \\
\hline Waist circumference & $88.3 \pm 15.8$ & $89.3 \pm 3.8$ & $\mathrm{p}=0.87$ \\
\hline
\end{tabular}

Table 2

Anthropometric measurements before-after treatment (mean \pm DS)

\begin{tabular}{|llll|}
\hline Capsiate group $(n=8)$ & W0 & W8 & difference \\
\hline Weight $(\mathrm{kg})$ & $70.4 \pm 10.7$ & $71.1 \pm 11.4$ & $+0.7(p=0.38)$ \\
\hline BMI $(\mathrm{kg} / \mathrm{m} 2)$ & $26.9 \pm 5.7$ & $27.1 \pm 6.0$ & $+0.2(p=0.36)$ \\
\hline Waist circumference & $88.3 \pm 15.8$ & $87.1 \pm 14.8$ & $-1.2(p=0.12)$ \\
\hline Placebo group $(n=6)$ & & & \\
\hline Weight $(\mathrm{kg})$ & $71.8 \pm 6.1$ & $71.5 \pm 6.2$ & $-0.3(p=0.77)$ \\
\hline BMI $(\mathrm{kg} / \mathrm{m} 2)$ & $27.2 \pm 2.1$ & $27.1 \pm 1.7$ & $-0.1(p=0.71$ \\
\hline Waist circumference & $89.3 \pm 3.8$ & $87.7 \pm 3.9$ & $-1.6(p=0.27)$ \\
\hline
\end{tabular}


Table 3

Indexes of bone mineralization - CAPSIATE group (mean \pm DS)

\begin{tabular}{|llll|}
\hline BMD $(\mathbf{g} / \mathbf{c m} 2)$ & W0 & W8 & difference \\
\hline Head & $2.329 \pm 0.183$ & $2.376 \pm 0.147$ & $+0.047(p=0.74)$ \\
\hline Arms & $0.871 \pm 0.062$ & $0.907 \pm 0.070$ & $+0.036(p=0.45)$ \\
\hline Legs & $1.130 \pm 0.067$ & $1.139 \pm 0.072$ & $+0.009(p=0.24)$ \\
\hline Trunk & $0.964 \pm 0.119$ & $0.989 \pm 0.085$ & $+0.025(p=0.22)$ \\
\hline Ribs & $0.797 \pm 0.129$ & $0.805 \pm 0.094$ & $+0.008(p=0.21)$ \\
\hline Vertebral column & $1.106 \pm 0.127$ & $1.158 \pm 0.149$ & $+0.052(p=0.04)$ \\
\hline Pelvis & $1.047 \pm 0.115$ & $1.061 \pm 0.076$ & $+0.014(p=0.72)$ \\
\hline Whole body & $1.172 \pm 0.078$ & $1.193 \pm 0.065$ & $+0.021(p=0.22)$ \\
\hline
\end{tabular}

Table 4

Indexes of bone mineralization - PLACEBO group (mean \pm DS)

\begin{tabular}{|llll|}
\hline BMD $(\mathbf{g} / \mathbf{c m} 2)$ & W0 & W8 & difference \\
\hline Head & $2.207 \pm 0.343$ & $2.290 \pm 0.262$ & $+0.083(p=0.36)$ \\
\hline Arms & $0.885 \pm 0.124$ & $0.911 \pm 0.096$ & $+0.026(p=0.70)$ \\
\hline Legs & $1.150 \pm 0.117$ & $1.186 \pm 0.083$ & $+0.036(p=0.80)$ \\
\hline Trunk & $0.971 \pm 0.137$ & $1.031 \pm 0.089$ & $+0.060(p=0.32)$ \\
\hline Ribs & $0.821 \pm 0.107$ & $0.862 \pm 0.052$ & $+0.041(p=0.64)$ \\
\hline Vertebral column & $1.099 \pm 0.178$ & $1.130 \pm 0.210$ & $+0.031(p=0.26)$ \\
\hline Pelvis & $1.040 \pm 0.156$ & $1.099 \pm 0.115$ & $+0.059(p=0.65)$ \\
\hline Whole body & $1.156 \pm 0.139$ & $1.207 \pm 0.091$ & $+0.051(p=0.71)$ \\
\hline
\end{tabular}

In a subsequent analysis, the compositions of $\mathrm{mROI}$ and sROI were evaluated before and after treatment (Tables 5). The CAPSIATE group showed a $9.1 \%$ increase $(p=0.05)$ in the adipose tissue and an $8.5 \%$ decrease in lean mass measured at SROI, whereas no statistically significant changes were detected in the placebo group. Conversely, the composition of mROI was not different after treatment in either the CAPSIATE or the placebo group. 
Table 5

ROI composition -CAPSIATE and placebo group (median, IQR)

$\begin{array}{lll}\text { Group W0 } & \text { W8 }\end{array}$

\section{Capsiate \\ $(n=8)$}

\begin{tabular}{|c|c|c|c|c|}
\hline \multirow[t]{2}{*}{$\operatorname{mROI}_{(\mathbf{g})}$} & Fat mass & $\begin{array}{l}1010.0(886.8- \\
1277.3)\end{array}$ & $\begin{array}{l}1063.0(938.5- \\
1326.5)\end{array}$ & $\begin{array}{l}+53.0 \\
(p=0.09)\end{array}$ \\
\hline & $\begin{array}{l}\text { Lean } \\
\text { mass }\end{array}$ & $\begin{array}{l}1550.5(1389.3- \\
1774.5)\end{array}$ & $\begin{array}{l}1529.5(1360.0- \\
1827.8)\end{array}$ & $\begin{array}{l}-21.0 \\
(p=0.58)\end{array}$ \\
\hline \multirow[t]{2}{*}{$\begin{array}{l}\text { sROI } \\
\text { (g) }\end{array}$} & Fat mass & $214.0(177.8-268.5)$ & 233.5 (190.0-290.5) & $\begin{array}{l}+19.5 \\
(p=0.05)\end{array}$ \\
\hline & $\begin{array}{l}\text { Lean } \\
\text { mass }\end{array}$ & $407.0(344.0-447.5)$ & 372.5 (346.0-403.0) & $\begin{array}{l}-34.5 \\
(p=0.05)\end{array}$ \\
\hline
\end{tabular}

\section{Placebo \\ $(n=6)$}

\begin{tabular}{lllll}
\hline $\begin{array}{l}\mathrm{mROI} \\
(\mathbf{g})\end{array}$ & Fat mass & $\begin{array}{l}1181.5(977.0- \\
1353.5)\end{array}$ & $\begin{array}{l}1199.0 \\
1468.5)\end{array}$ & $\begin{array}{l}+17.5 \\
(\mathrm{p}=0.25)\end{array}$ \\
\cline { 2 - 5 } & $\begin{array}{l}\text { Lean } \\
\text { mass }\end{array}$ & $\begin{array}{l}1703.5(1543.0- \\
2003.0)\end{array}$ & $\begin{array}{l}1557.0(1361.0- \\
2103.0)\end{array}$ & $\begin{array}{l}-146.5 \\
(\mathrm{p}=0.35)\end{array}$ \\
\hline $\begin{array}{l}\text { sROI } \\
(\mathrm{g})\end{array}$ & Fat mass & $236.5(191.5-281.3)$ & $236.0(188.8-318.5)$ & $-0.5(p=0.75)$ \\
\cline { 2 - 5 } & $\begin{array}{l}\text { Lean } \\
\text { mass }\end{array}$ & $417.5(358.3-441.5)$ & $408.5(319.0-441.5)$ & $+1.0(p=0.75)$ \\
\hline
\end{tabular}

\section{Discussion}

Although recent findings from animal models and human studies have shown a promising effect of capsinoids on body weight reduction $[9,10]$, the effect of continuous administration of capsiate for 8 weeks on body weight in our population was negligible. Anyway, some unexpected results emerged concerning BMD and body composition.

First, we observed a significant increase in BMD of the spine after 8 weeks of treatment with capsiate. This result appears in contrast with a recent observational study conducted on a large population of over 500,000 Chinese subjects showing an increased fracture risk in subjects with higher consumption of spicy food (OR up to 1.18 for subjects reporting daily consumption of spicy food) [11]. As suggested by the authors, the action of capsaicin on bone metabolism could be dependent from the activation of the TRPV1 receptor, the same present in the digestive tract and that mediates the effects of capsaicin on induction of thermogenesis by brown adipose tissue (BAT) and mobilization of lipid reserves through the orthosympatetic nervous system $[12,13]$. This receptor is actually a non-selective cation channel and it is expressed on most of the unmyelinated nerve fibers and on some small myelinated sensitive nerve fibers $[8,14]$, acting as a nociceptor [14-16]. CGRP (calcitonin-gene related peptide), on the other hand, is a neuropeptide widely distributed in the central and peripheral nervous system [17] whose release from 
sensory nerve terminals appears to be stimulated by the local administration of capsaicin [18] and inhibited by TRPV1 antagonists [19]. In vitro and in vivo experimental studies have demonstrated the inhibitory effect of CGRP on osteoclastic activity and, consequently, on bone resorption [20], perhaps even modulating the action of calcitonin [21]. Furthermore, the CGRP receptor appears to be expressed also on osteoblasts, of which it regulates the differentiation from medullary progenitors [20]. In the literature, there is not concordance on the effect of capsaicin on bone metabolism, as several experimental studies have provided conflicting results. Rossi et al., for example, reported that genetic or pharmacological (by administration of palvanil) inactivation of TRPV1 receptor appears to be protective against osteoclastic activity, reducing bone resorption in mice [22]. Similarly, Offley et al. administered capsaicin or placebo to 16 rats that subsequently underwent DXA examination and bone histomorphometry. After 4 weeks of treatment with capsaicin, the authors reported a decrease in BMD on the metaphysis of the tibia and femur. At histology, the number of osteoclasts and the resorption surface increased in the proximal tract of the tibia, while the osteoblastic activity and the volume of trabecular bone decreased. Fifty-seven percent destruction of the unmyelinated fibers was also reported, with reduced levels of CGRP in the sciatic nerve and in the proximal tract of the tibia [23]. In another study, rats were treated with capsaicin in a single dose, then after 14 days of treatment underwent tooth extraction and were killed after further 4 days. The study presented both a control group and a placebo group. Differently from the results of the above-mentioned studies, in the group of animals treated with capsaicin there was a $40 \%$ and $54 \%$ reduction in bone resorption surface compared to placebo and controls, respectively, and an absolute $26 \%$ and $34 \%$ reduction of osteoclasts and cells in active reabsorption [24]. Similarly, Hill et al., in another experimental study conducted on animals (47 rats in 3 groups: guanethidine, capsaicin, control) reported that sympathetic denervation at birth by capsaicin causes a $21 \%$ reduction in alveolar bone resorption after tooth extraction in adult animals [25]. A partial explanation for the different effects of capsaicin in animal models has been provided by Holzer. Indeed, he states that most studies on capsaicin have been conducted on small rodents (mice, rats, guinea pigs) and it is important to note that the effects of low doses of capsaicin differ quantitatively and qualitatively from higher doses. At low doses (in the $\mathrm{pg} / \mathrm{kg}$ range), capsaicin exerts a powerful excitatory effect on peripheral nerve endings (apparently only on type $\mathrm{C}$ unmyelinated fibers). The initial excitement, however, is soon followed by drug desensitization and nerve conduction block. In addition, the systemic administration of high doses of capsaicin (in the $\mathrm{mg} / \mathrm{kg}$ range) has a toxic effects on sensory neurons, with the extent of the damage that depends on dosage, route of administration, species and age of the animal [18].

Concerning the effects of capsaicin in humans, there are no studies in the current literature evaluating bone metabolism. Interestingly, the preliminary findings of our study suggest that the administration of capsaicin may determine an improvement in bone mineralization, especially at spine level, which represents the skeletal segment richest in trabecular bone. Since extracellular calcium levels act on preadipocytes inducing adipogenesis [7], it could be hypothesized that adipose tissue deposition could be contrasted by biological mechanisms aimed at reducing circulating calcium levels, that typically underlie an antiresorptive mechanism on bone. Another possible explanation could be related to the ability of capsaicin to induce brown fat differentiation, as suggested by other authors [26]. The presence of brown 
fat, indeed, has been associated with better BMD values in women [27, 28], suggesting its possible direct involvement in bone metabolism. On this purpose, Nirengi et al. used near-infrared spectroscopy to estimate the activity of brown fat in the supraclavicular region of 20 subjects ( 20 years old, 10 males and 10 females, normal weight) treated with $9 \mathrm{mg}$ of capsinoids/day for 8 weeks, but neither body composition (except for visceral fat) nor bone mass assessed by DXA showed significant changes after treatment [29]. In another study by Yoneshiro et al., 18 men underwent positron emission tomography (PET) examination (in a standardized cold condition) to distinguish BAT-positive from BAT-negative subjects, then they were all treated with a single dose of capsinoids $(9 \mathrm{mg})$ or placebo, subjected to calorimetry and, after 1-3 weeks, the experiment was repeated with crossover mode. Since the highest energy expenditure response occurred in BAT-positive subjects after administration of capsinoids, the authors concluded that capsinoids, acting at the intestinal level through TRPV1, can activate the already present BAT and they also hypothesized that the capsinoids may induce the recruitment of new BAT in subjects who do not have it [30]. In our sample, patients treated with capsiate showed a significant change in composition of the supraclavicular region with an increase in the percentage of adipose tissue and a reduction in the percentage of lean mass. Considering that supraclavicular region is an important site for BAT in adults [31], these data are relatively disappointing, since in the group treated with capsiate we would have expected an opposite variation, as an expression of a conversion of white adipose tissue into BAT, with an increase in lean mass and a decrease of fat mass. In fact, given the higher density of BAT, we would have expected an increase in the amount of tissue detected as lean, corresponding to the new BAT, at the expense of a reduction of the pre-existing white adipose tissue. Such a change would seem to be indirectly suggested by the radiological characteristics of BAT on computerized tomography (CT): BAT, compared to white adipose tissue, is characterized by higher density (assessed as Hounsfield Units) [32], even it in the literature data concerning the characteristics of BAT detected by DXA are lacking. In any case, this finding appears to be worthy of further study.

Epidemiological studies suggest that a reduction of 1 standard deviation (SD) in BMD is associated with an increase in the relative fracture risk of approximately 1.5-2 [33] and a change of 1 DS corresponds approximatively to a $10 \%$ change in the BMD [34]. It goes without saying that an increase in BMD of $4.7 \%$ represent a clinically relevant finding. In addition, such an increase was found after only 8 weeks of treatment, while in clinical practice densitometric checks are performed at 18-24 months intervals.

Despite these promising results, we are aware that there are important limitations in our study. First, the sample size is extremely low. This may have limited our ability to detect statistically significant changes in weight or body composition. In addition, the short treatment period, and the short time between DXA assessments may have reduced the magnitude of the effect induced by capsiate intake on BMD, leading us to underestimate it.

\section{Conclusion}

The administration of $9 \mathrm{mg} /$ day of capsiate for 8 weeks in a sample of slighty overweight women led to negligible changes in body weight and waist circumference. Interestingly, a significant increase in BMD 
measured by DXA at spine was detected after treatment, suggesting that capsiate may be beneficial on bone metabolism, even if further studies are needed. Notably, treatment with capsiate was associated with an increase in fat mass and a decrease in lean mass assessed by DXA at the supraclavicular region. The biological significancy of this finding needs to be confirmed by wider studies.

\section{Declarations}

\section{Funding}

Capsiate and placebo capsules were provided by Ajinomoto Co., Inc. (Tokyo, Japan).

\section{Competing interest}

All authors declare that they have no conflict of interests.

\section{Ethics approval}

This study was performed in line with the principles of the Declaration of Helsinki. Approval was granted by the local ethics committee (number of protocol 2015-0222 OR).

\section{Consent to participate}

Informed consent was obtained from all individual participants included in the study.

\section{Acknowledgements}

Nothing to declare.

\section{References}

1. Arroyo-Johnson C, Mincey KD (2016) Obesity Epidemiology Trends by Race/Ethnicity, Gender, and Education. Gastroenterol Clin North Am 45:571-579. https://doi.org/10.1016/j.gtc.2016.07.012.0besity

2. Chooi YC, Ding C, Magkos F (2019) The epidemiology of obesity. Metabolism 92:6-10. https://doi.org/10.1016/j.metabol.2018.09.005

3. Gallus S, Odone A, Lugo A et al (2013) Overweight and obesity prevalence and determinants in Italy: An update to 2010. Eur J Nutr 52:677-685. https://doi.org/10.1007/s00394-012-0372-y

4. Blüher M (2019) Obesity: global epidemiology and pathogenesis. Nat Rev Endocrinol 15:288-298. https://doi.org/10.1038/s41574-019-0176-8

5. Dragano NRV, Fernø J, Diéguez C et al (2020) Recent Updates on Obesity Treatments: Available Drugs and Future Directions. Neuroscience 437:215-239. https://doi.org/10.1016/j.neuroscience.2020.04.034 
6. Gupta R, Kapoor B, Gulati M et al (2021) Sweet pepper and its principle constituent capsiate: functional properties and health benefits. Crit Rev Food Sci Nutr 0:1-25. https://doi.org/10.1080/10408398.2021.1913989

7. Bishnoi M, Kondepudi KK, Baboota RK et al (2013) Role of transient receptor potential channels in adipocyte biology. Expert Rev Endocrinol Metab 8:173-182. https://doi.org/10.1586/eem.13.4

8. Caterina MJ, Julius D (2003) The Vanilloid Receptor: A Molecular Gateway to the Pain Pathway. http://dx.doi.org/101146/annurev.neuro241487 24:487-517. https://doi.org/10.1146/ANNUREV.NEURO.24.1.487

9. Zsiborás C, Mátics R, Hegyi P et al (2018) Capsaicin and capsiate could be appropriate agents for treatment of obesity: A meta-analysis of human studies. Crit Rev Food Sci Nutr 58:1419-1427. https://doi.org/10.1080/10408398.2016.1262324

10. Ohyama K, Nogusa $Y$, Shinoda $\mathrm{K}$ et al (2016) A synergistic antiobesity effect by a combination of capsinoids and cold temperature through promoting beige adipocyte biogenesis. Diabetes 65:14101423. https://doi.org/10.2337/db15-0662

11. Mei C, Fang Z, Yin R et al (2019) Spicy food and self-reported fractures. Clin Nutr 38:2239-2245. https://doi.org/10.1016/j.clnu.2018.09.027

12. lida T, Moriyama T, Kobata $\mathrm{K}$ et al (2003) TRPV1 activation and induction of nociceptive response by a non-pungent capsaicin-like compound, capsiate. Neuropharmacology 44:958-967. https://doi.org/10.1016/S0028-3908(03)00100-X

13. Ono K, Tsukamoto-Yasui M, Hara-Kimura $Y$ et al (2011) Intragastric administration of capsiate, a transient receptor potential channel agonist, triggers thermogenic sympathetic responses. 110:789798. https://doi.org/10.1152/JAPPLPHYSIOL.00128.2010. https://doi.org/101152/japplphysiol001282010

14. Caterina MJ, Schumacher MA, Tominaga M et al (1997) The capsaicin receptor: a heat-activated ion channel in the pain pathway. Nature 389:816-824. https://doi.org/10.1038/39807

15. Avelino A, Cruz F (2006) TRPV1 (vanilloid receptor) in the urinary tract: expression, function and clinical applications. Naunyn Schmiedebergs Arch Pharmacol 373:287-299. https://doi.org/10.1007/s00210-006-0073-2

16. Moran MM, McAlexander MA, Bíró T, Szallasi A (2011) Transient receptor potential channels as therapeutic targets. Nat Rev Drug Discov 2011108 10:601-620. https://doi.org/10.1038/nrd3456

17. Voets T, Talavera K, Owsianik G, Nilius B (2005) Sensing with TRP channels. Nat Chem Biol 200512 1:85-92. https://doi.org/10.1038/nchembio0705-85

18. Holzer P (1988) Local effector functions of capsaicin-sensitive sensory nerve endings: Involvement of tachykinins, calcitonin gene-related peptide and other neuropeptides. Neuroscience 24:739-768. https://doi.org/10.1016/0306-4522(88)90064-4

19. Franco-Cereceda A, Lundberg JM (1992) Capsazepine inhibits low pH- and lactic acid-evoked release of calcitonin gene-related peptide from sensory nerves in guinea-pig heart. Eur J Pharmacol 221:183-184. https://doi.org/10.1016/0014-2999(92)90792-3 
20. Wang L, Shi X, Zhao R et al (2010) Calcitonin-gene-related peptide stimulates stromal cell osteogenic differentiation and inhibits RANKL induced NF-KB activation, osteoclastogenesis and bone resorption. Bone 46:1369-1379. https://doi.org/10.1016/j.bone.2009.11.029

21. Goltzman D, Mitchell J (1985) Interaction of Calcitonin and Calcitonin Gene-Related Peptide at Receptor Sites in Target Tissues. Sci (80-) 227:1343-1345. https://doi.org/10.1126/SCIENCE.2983422

22. Rossi F, Bellini G, Torella M et al (2014) The genetic ablation or pharmacological inhibition of TRPV1 signalling is beneficial for the restoration of quiescent osteoclast activity in ovariectomized mice. $\mathrm{Br}$ J Pharmacol 171:2621-2630. https://doi.org/10.1111/bph.12542

23. Offley SC, Guo T-Z, Wei T et al (2004) Capsaicin-Sensitive Sensory Neurons Contribute to the Maintenance of Trabecular Bone Integrity. J Bone Miner Res 20:257-267. https://doi.org/10.1359/JBMR.041108

24. Adam C, Llorens A, Baroukh B et al (2000) Effects of capsaicin-induced sensory denervation on osteoclastic resorption in adult rats. Exp Physiol 85:S0958067000019308. https://doi.org/10.1017/S0958067000019308

25. Hill EL, Turner R, Elde R (1991) Effects of neonatal sympathectomy and capsaicin treatment on bone remodeling in rats. Neuroscience 44:747-755. https://doi.org/10.1016/0306-4522(91)90094-5

26. H RK et al (2016) Direct action of capsaicin in brown adipogenesis and activation of brown adipocytes. Cell Biochem Funct 34:34-41. https://doi.org/10.1002/CBF.3162

27. Bredella MA, Fazeli PK, Freedman LM et al (2012) Young Women with Cold-Activated Brown Adipose Tissue Have Higher Bone Mineral Density and Lower Pref-1 than Women without Brown Adipose Tissue: A Study in Women with Anorexia Nervosa, Women Recovered from Anorexia Nervosa, and Normal-Weight Women. J Clin Endocrinol Metab 97:E584-E590. https://doi.org/10.1210/jc.20112246

28. Lee P, Brychta RJ, Collins MT et al (2013) Cold-activated brown adipose tissue is an independent predictor of higher bone mineral density in women. Osteoporos Int 24:1513-1518. https://doi.org/10.1007/s00198-012-2110-y

29. Nirengi $\mathrm{S}$, Homma T, Inoue $\mathrm{N}$ et al (2016) Assessment of human brown adipose tissue density during daily ingestion of thermogenic capsinoids using near-infrared time-resolved spectroscopy. J Biomed Opt 21:091305. https://doi.org/10.1117/1.JBO.21.9.091305

30. Yoneshiro T, Aita S, Kawai Y et al (2012) Nonpungent capsaicin analogs (capsinoids) increase energy expenditure through the activation of brown adipose tissue in humans. Am J Clin Nutr 95:845-850. https://doi.org/10.3945/ajcn.111.018606

31. Cinti S (2018) Adipose Organ Development and Remodeling. Compr Physiol 8:1357-1431. https://doi.org/10.1002/cphy.c170042

32. Hu HH, Tovar JP, Pavlova $Z$ et al (2012) Unequivocal identification of brown adipose tissue in a human infant. J Magn Reson Imaging 35:938-942. https://doi.org/10.1002/jmri.23531 
33. Kanis JA, Borgstrom F, De Laet C et al (2005) Assessment of fracture risk. Osteoporos Int 16:581589. https://doi.org/10.1007/s00198-004-1780-5

34. Tai V, Leung W, Grey A et al (2015) Calcium intake and bone mineral density: systematic review and meta-analysis. BMJ 351. https://doi.org/10.1136/BMJ.H4183

\section{Figures}

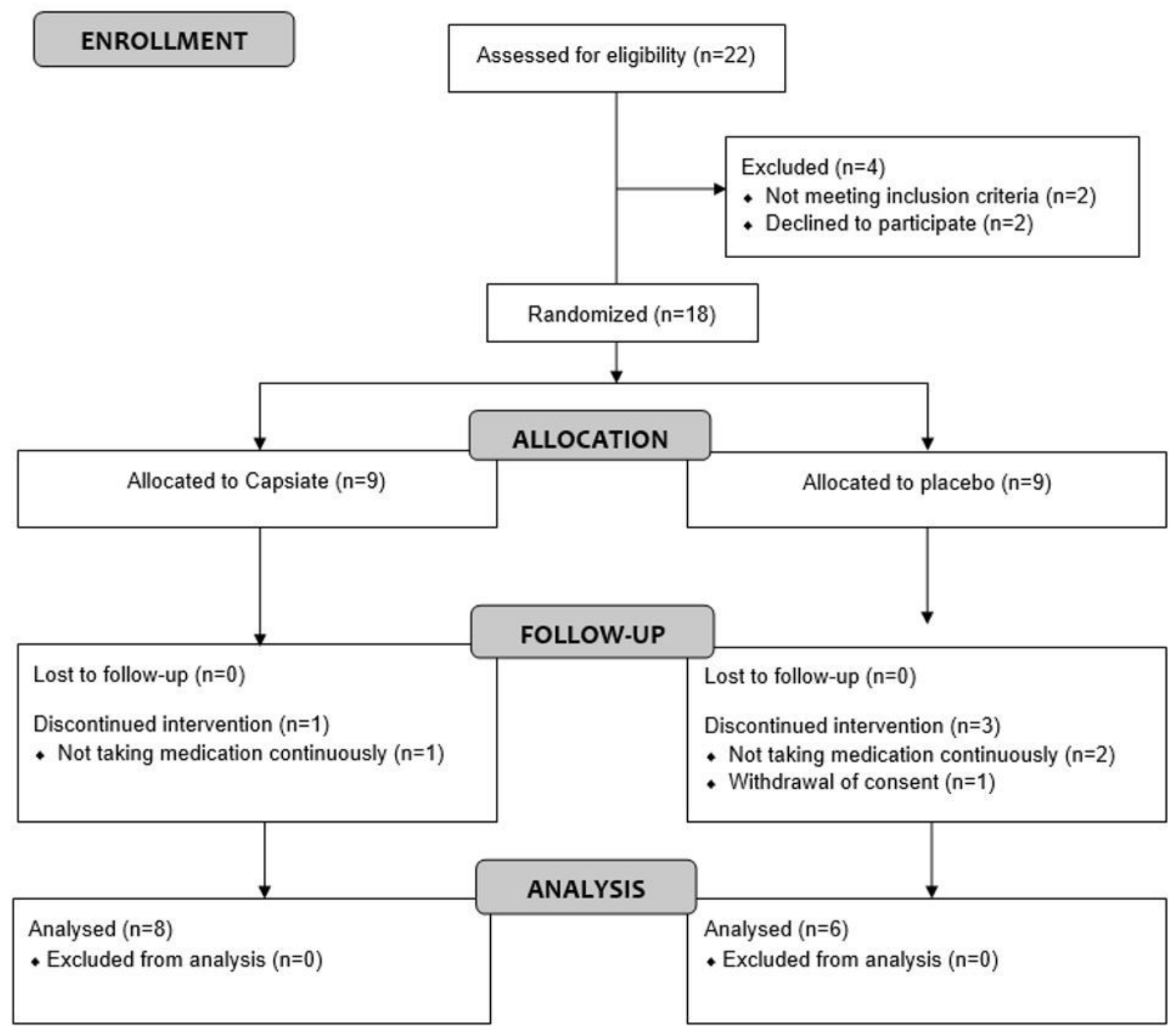

Figure 1

CONSORT 2010 Flow Diagram 